\title{
Impact of Media-Related SIFs on QoE for H.265/HEVC Video Streaming
}

\author{
Irma Osmanović, Jasmina Baraković Husić, Member, IEEE and Sabina Baraković
}

\begin{abstract}
Long term evolution (LTE) has distinguished itself compared to other mobile broadband technologies in its ability to handle the growth of video traffic that has become an important part of user's mobile broadband experience. Growing trend of video consumption implies that that media-related system influence factors (SIFs) should be identified and well understood in order to determine how they affect the user's quality of experience (QoE). Therefore, this paper aims to provide a deeper understanding of media-related SIFs and their impact on QoE for video streaming. Experimental study has included two phases, i.e., H.265/ high efficiency video coding (HEVC) coded video streaming emulation over LTE network and end-user survey for collecting mean opinion score (MOS). The original scientific contribution of this study and its results is twofold. For the first time it has been shown that there exists strong and statistically significant impact of media-related SIFs and their interactions on QoE for H.265/HEVC video streaming, and a quantification of relation between QoE and selected media-related SIFs, i.e., prediction model has been provided. The knowledge of these impacts and interactions, as well as prediction model, contributes to increase the awareness of and improvement of video streaming service. This leads to better understanding of end user's QoE and provides a starting point for development of multidimensional QoE model.
\end{abstract}

Index Terms-ANOVA; H.265; LTE; media-related SIF; MOS; QoE; video streaming.

\section{INTRODUCTION}

$\mathrm{M}$ OBILE video traffic is the fastest growing segment of mobile data traffic driven by proliferation of smartphone subscriptions and increasing average data volume per subscription. Currently, video accounts for over $50 \%$ of all mobile traffic and is expected to increase to over $75 \%$ by the end of 2023 [1]. However, mobile video traffic forecast may be

Manuscript received March 26, 2018; revised June 1, 2018 and June 13, 2018. Date of publication June 27, 2018. Prof. Nikola Rožić has been coordinating the review of this manuscript and approved it for publication.

I. Osmanović is with the Systech, d.o.o. Sarajevo, 71217 Sarajevo, Bosnia and Herzegovina (e-mail: irmaosmanovic93io@gmail.com).

J. Baraković Husić is with the University of Sarajevo and BH Telecom, Joint Stock Company, Sarajevo, 71000 Sarajevo, Bosnia and Herzegovina (email: jasmina.barakovic@etf.unsa.ba).

S. Baraković is with the University of Sarajevo, American University in Bosnia and Herzegovina, and Ministry of Security of Bosnia and Herzegovina (e-mail: barakovic.sabina@gmail.com).

Digital Object Identifier (DOI): 10.24138/jcomss.v14i2.516 shifted by the appearance of new applications and changes in user behaviour. Millennials being born between early 1980s and the early 2000s [1] play a crucial role in shaping mobile video traffic consumptions. Leading the change in video consumption trends, millennials have high expectations on network performance. This suggests that telecom operators need to focus on how to meet the expectations of this user segment without ignoring the fact that networks need to be designed to support mobile video [2]. Therefore, discussion about mobile video traffic growth is usually directed towards long-term evolution (LTE). This technology has distinguished itself compared to other mobile broadband technologies in its ability of handle growing volume of video traffic. Apart from need to understand the impact that video traffic growth will have on their networks, telecom operators have to shift from technical quality requirements to user quality of experience (QoE) [3].

QoE is influenced by service, content, device, application, and context of use [4]. Therefore, it is necessary to identify and understand multiple influence factors (IFs) in the service delivery chain, and determine how they affect QoE [5]. This is an essential prerequisite for QoE management, which determines the parameters to be monitored and measured, and finally used to develop, test, and implement the QoE control and optimization strategies [6]. In this regard, IF has been defined as any feature of a user, system, service, application, or content whose current state or features affect QoE [4]. Currently adopted classification divides IFs into three categories [4]: human, context, and system IFs. This paper deals with the system IFs (SIFs) referring to features that determine the technically produced quality of service.

SIFs are further divided into four sub-categories [4]: content-, media-, network-, and device-related SIFs. Here the focus is on media-related SIFs whose optimization enables the same level of subjective quality with significant savings in network infrastructure. More specifically, this paper aims to provide deeper and more comprehensive understanding of media configuration parameters and their impact on QoE in the context of video streaming over LTE given that, according to the related work provided in the following section, there is a limited number of papers dealing with this challenge. In this regard, video coding H.265/ high efficiency video coding (HEVC) is used as compression standard since it provides the best quality and performance compared to other codecs [7]. In order to accomplish abovementioned aim, we have performed 
an experimental study that includes end-user survey to collect mean opinion score (MOS) grades for video streaming over LTE which are further processed by statistical method general linear model (GLM): analysis of variance (ANOVA) [8]. In addition, taking into account the results of previous major studies, summarized in detail in the following section, we have concluded that what is also missing is the quantification of impacts of media configuration parameters on QoE for video streaming. That is why we have produced a prediction model quantifying the aforementioned relations between the selected media-related SIFs and QoE (shown in MOS) by using multiple linear regression (MLR) technique.

In general, there are many approaches, which attempt to solve many problems in data analysis, such as statistics, machine learning, or neural networks. However, the suitability of given approaches to the problem depends on the nature of the problem, i.e., the nature of the desired output results. Researchers analyse their data by using different modelling techniques depending on: (i) the aim of the study; (ii) types of models that one wants to obtain; (iii) the number of dependent and independent variables (single or multiple) that are considered; as well as (iv) the nature of variables. Hence, focusing only on studies that deal with user gained results such as MOS, i.e., QoE is, the authors have mostly used statistical techniques that range from simple descriptive statistics to more complex methods, such as various types of linear and non-linear regressions.

We have chosen ANOVA and MLR for achieving two different goals in this paper. The first one was to find out how QoE is related to the selected media-related SIFs, and whether the interactions of these factors impact QoE. ANOVA test was found to be suitable for this objective, as described in [8, ch 1]. The second one was to quantify the relation between QoE and the selected media-related SIFs. In other words, we wanted to find out how our numerical QoE (expressed in MOS) is related to the selected predictor variables which are numerical. MLR statistical technique has shown to be the right approach after consulting [8, ch 1]. In addition, GLM has one more technique - analysis of covariance (ANCOVA) which can be used to describe how a numerical dependent variable is related to categorical independent variables and numerical predictor variables at the same time [8, ch 1]. Since this is not the case in our study, this method of analysis has not be considered.

Therefore, the original scientific contribution of this study and its results is twofold. Firstly, it has been shown that the impact of media-related SIFs and their mutual interactions on QoE for H.265/HEVC video streaming is strong and statistically significant. Secondly, the relationship between selected media-related SIFs and QoE for H.265/HEVC video streaming is quantified, i.e., we have obtained a prediction equation model. According to the authors' best knowledge after reviewing the literature (Section II), this is the first time that the description and quantification of abovementioned relations has been provided in such a manner. Consequently, based on the proposed model, one is able to identify the importance of distinct media-related SIFs in terms of QoE.
Also, the model indicates and justifies the need for multidimensional approach to QoE in order for this important concept to be addressed properly $[5,6]$. The knowledge gained from this study and obtained results may contribute to the interested stakeholders to: (i) become aware of these impacts and interactions, (ii) improve video streaming service, which leads to better end user's QoE, and (iii) provide the basis for future multidimensional QoE model which will help in better QoE management process.

The rest of the paper is organized as follows. Section II presents the related work considering media-related SIFs and their impact on QoE for video streaming over LTE network. Section III describes the experimental study, which includes two phases, i.e., video streaming emulation over LTE network and end-user survey for collecting MOS grades. Section IV presents and discusses experimental results obtained from statistical analyses. Section V concludes the paper with an outlook on open issues.

\section{RELATED WORK}

This section provides a non-exhaustive review of research activities directed to media-related SIFs and their impact on QoE for video streaming. Being a measure of the delight or annoyance of user with a given service [4], QoE is affected among others [9-11] by media-related SIFs. They refer to different media configuration parameters, such as coding, bitrate, resolution, sampling rate, frame rate, media synchronization, etc. Here we discuss their impact on the quality perception of H.265/HEVC video streaming. Table I summarizes the related work considering the mutual impact of multiple media-related SIFs on subjective/objective quality perception of video streaming.

Video coding affects the quality perception of video streaming as stated in literature [12-31]. A variety of video coding standards have been analysed in this context, such as H.264/ advanced video coding (AVC) or H.265/HEVC. It has been shown that H.265/HEVC allows 50\% higher compression than its predecessor H.264/AVC without changes in subjective quality perception [23, 24, 32, 33]. In addition, it has been realized that $\mathrm{H} .265 / \mathrm{HEVC}$ has $6 \mathrm{~dB}$ higher peak signal to noise ratio (PSNR) than H.264/AVC due to variable length of code blocks [24, 25]. Furthermore, H.265/HEVC enables a higher degree of variation of codec parameters, such as coding block size, motion vector size, etc. in order to increase network resource savings while keeping the same quality degree [18, 19, 23]. Therefore, this codec has been chosen as video compression standard in our experimental study.

Impact of video coding on the quality perception has been usually analysed in relation to bitrate and resolution. Higher bitrate enables higher degree of user satisfaction [16, 34], but also requires higher resolution and more network resources which can be challenging when bandwidth is limited [15, 21]. Furthermore, bitrate is related to the transmission efficiency. Simulation of video transmission with different resolutions has shown that higher resolution means higher quality [12, 20, 21, 
$24,26,28]$, but also requires more bits to transmit through a network.

In addition, low frame rate decreases the video quality perception [16, 21, 22, 26, 28], while high frame rate increases the quality only to a certain extent. Frame rate depends on many SIFs, such as dynamics of video movement or network conditions [13, 14, 35] which should be considered in video adaptation [18]. Furthermore, high sampling rate increases the quality perception, but requires more resources and processing time. Therefore, it is necessary to take care of the price-quality ratio to find their optimal relationship [15, 28, 31].

Aforementioned media-related SIFs have been manipulated at different levels in order to describe their impact on quality perception of the given service. In order to measure quality perception of video streaming service, subjective and objective quality assessment can be used. Considering the related work summarized in Table I, one can conclude that video quality perception has been measured using subjective quality assessment $(45 \%)$, objective quality assessment $(35 \%)$, and both of them $(20 \%)$. Although it is more complicated, subjective quality assessment has been selected for our experimental study since it provides more reliable results compared to the objective one. Accordingly, subjective quality metric, i.e. mean opinion score (MOS), is used to express the user' quality perception, while the objective ones, such as PSNR, structural similarity (SSIM), or video quality metric (VQM), are not considered in our experimental study.

Considering the aim of this paper, the related work review focuses on the identification of media-related SIFs and their impact on subjective/objective quality perception of video streaming service. Summarizing the related work presented in Table I, one may conclude that video quality perception has been analysed in terms of frame rate $(29 \%)$, bitrate $(25 \%)$, resolution $(23 \%)$, codec $(12 \%)$, sampling rate $(6 \%)$, and media synchronization $(2 \%)$. However, previous research studies have neglected to consider the simultaneous impact of these media-related SIFs on the quality perception of video streaming service, which can be explained by the complexity that such studies incur. Also, existing studies missed to quantify QoE and its relation to media-related SIFs in this context. Therefore, this paper intends to provide deeper and more comprehensive understanding of selected media-related SIFs and their interactions in the context of quality perception of video streaming, together with their quantification, i.e., modelling. Although H.265/HEVC is the most effective video compression standard [32], it has received not nearly as much attention as its predecessor H.264/AVC. This motivated us to investigate the impact of media-related SIFs and their interactions on QoE in the context of H.265/HEVC coded video streaming.

\section{RESEARCH METHODOLOGY}

Based on the literature review summarized in previous section, the objectives of this paper can be derived as follows: (i) examination of impact of media-related SIFs and their interactions on the QoE for H.265/HEVC video streaming; and (ii) quantification of relation between media-related SIFs and QoE for H.265/HEVC video streaming.

According to Table I, one can conclude that quality perception of H.265/HEVC video streaming has been usually analysed in terms of bitrate and resolution. This is the reason why we have selected these media-related SIFs to be our main research focus with addition of compression artefacts that were discussed in [36]. As shown in Table II, these media-related SIFs can be manipulated by changing ffmpeg-specific parameters [37], i.e., resolution, coding tree unit (CTU), and, constant rate factor (CRF). Accordingly, seven hypotheses have been formulated and tested by using appropriate statistical methods.

H1: The differences in QoE for video streaming caused by the change in resolution are not statistically significant.

H2: The differences in QoE for video streaming caused by the change in CTU parameter are not statistically significant.

H3: The differences in QoE for video streaming caused by the change in CRF parameter are not statistically significant.

H4: The differences in QoE for video streaming caused by the change in interaction between resolution and CTU parameter are not statistically significant.

H5: The differences in QoE for video streaming caused by the change in interaction between resolution and CRF parameter are not statistically significant.

H6: The differences in QoE for video streaming caused by the change in interaction between CTU and CRF parameters are not statistically significant.

H7: The differences in QoE for video streaming caused by the change in interaction of resolution, CTU, and CRF parameters are not statistically significant.

The aforementioned hypothesis are formed in the way that we do not expect the existence of statistically significant impact of individual ffmpeg parameters (i.e., resolution, CTU, and CRF) and their interactions on QoE. The reason for such hypotheses formulations comes from the rules of GLM: ANOVA statistical test ( $p>0.05)$, according to which the null hypothesis for the test is that the all means are equal (i.e., no difference between them). However, it is expected to have statistically significant impacts of individual parameters and their interactions on QoE $(p<0.05)$ because considered ffmpeg parameters affect the media-related SIFs and consequently influence the QoE.

In general, the ANOVA, as one of GLM techniques, refers to statistical models and associated procedures in which the observed variance is partitioned into components due to different explanatory variables. In other words, the purpose of ANOVA is to test for significant differences between two or more means which are symbolized by $\mu$. The null hypothesis in ANOVA test $\left(H_{0}\right)$ is that all the population group means are equal (1) versus the alternative one $\left(H_{a}\right)$ that at least one of the population means differs from the others (2):

$H_{0}: \mu_{1}=\mu_{2}=\cdots=\mu_{n}$
$H_{a}:$ not all $\mu_{i}(i=1, \cdots, n)$ are equal

However, in order to conduct the ANOVA test, one must test the data for basic assumptions: (i) normal distribution, i.e., 
the dependent variable must be normally distributed for each category of the independent variable; (ii) independence, i.e., cases must be independent; and (iii) homoscedasticity, i.e., variances of data are the same in all the groups (homogeneity of variance assumptions). More on this statistical analysis, one may find in the work of [8].

As stated earlier, we expect to have significant impacts of selected media-related SIFs on QoE for video streaming, and therefore, our eighth hypothesis which is related to quantification of those impacts is formulated as follows:

H8: QoE for video streaming is impacted by the following media-related SIFs according to the listed order, going from most to least influential: CTU, CRF, and resolution.

To describe the relationship between QoE and selected factors and whether the variability of QoE is explained by the variability of these factors and to which degree, a MLR analysis with three media-related SIFs as predictors was performed.

Multiple linear regression is a statistical technique that allows the prediction of someone's score of one variable on the basis of their scores on several other variables. This technique allows the identification of set of predictor variables which together provide a useful estimate of a participant's likely score on a dependent variable. In other words, one may use MLR to test and develop theories and models about precisely which set of variables is influencing our behaviour.

The basic idea or MLR method is that an equation is found, such as follows:

$y_{i}=\beta_{0}+\beta_{1} x_{i 1}+\beta_{2} x_{i 2}+\cdots++\beta_{j} x_{i j}+\cdots++\beta_{p} x_{i p}+\varepsilon_{i}$,

where $i=1$ to $n$ is a set of observations where each observation was selected because of its specific $x$-values, i.e., the values of $p(j=2$ to $p)$ predictor variables $x_{1}, x_{2}, \ldots, x_{j}, \ldots, x_{p}$ that were fixed by the investigator, whereas the $y$-value for each observation was sampled from a population of possible $y$ values, $\beta_{0}$ is the intercept, $\beta_{j}$ are regression coefficients, and $\varepsilon_{i}$ is the error term.

How well the equation fits the data is expressed by the coefficient of multiple determination, i.e., $R^{2}$. The definition of coefficient of determination is straight-forward; it is the percentage of the dependent variable variation that is explained by a linear model. It is calculated by using the following formula:

$R^{2}=1-\frac{\Sigma_{i}\left(y_{i}-\overline{\hat{y}_{l}}\right)^{2}}{\Sigma_{i}\left(y_{i}-\bar{y}\right)^{2}}$

where $\mathrm{y}$ is the observation of dependent variable, $\bar{y}$ is the mean of the observation, and $\hat{y}_{i}$ is the prediction of the dependent variable.

This coefficient may range from 0 , which means there is no relationship between the predictor and dependent variable, to 1 , which means a perfect fit and that there is no difference between the observed and expected values of dependent variable. In general, the higher $R^{2}$ is, the better the model fits the data. However, in practice, researchers usually use the adjusted $R^{2}$ that is only the adjustment of $R^{2}$ that penalizes the addition of extraneous predictors to the model. As it is the case with ANOVA, in order to perform the analysis, the collected data needs to satisfy the MLR assumptions: (i) normal distribution, i.e., the dependent variable must be normally distributed for each category of the independent variable; (ii) independence, i.e., cases must be independent; and (iii) homoscedasticity, i.e., variances of data are the same in all the groups (homogeneity of variance assumptions).

In order to obtain the data necessary to examine the impact of ffmpeg parameters (i.e., resolution, CTU, and CRF) on QoE, the experimental study has been performed. The experimental procedure included two phases as shown in Fig 1: (i) video streaming emulation over LTE, and (ii) end-user survey with the aim of collecting MOS values.

\section{A. Video Streaming Emulation over LTE}

The first phase involves three steps: (i) preparation of reference and test video sequences, (ii) configuration of LTE emulation environment, and (iii) reconstruction of test video sequences.

To perform this experimental study, we used San Francisco Cable Car Stock video clip in .mp4 format [38]. This video clip is characterized by duration of 39 seconds, resolution of $1920 \times 1080$ pixels, and frame rate of $30 \mathrm{fps}$. Audio content was removed from original video clip, which was shortened to 20 seconds. The selected media-related SIFs (i.e., resolution, bitrate, and compression) were manipulated according to the possibilities of the ffmpeg tool [37]. Each ffmpeg parameter is related to specific media-related SIF or a combination of those factors. Definition of ffmpeg parameters and their relation to media-related SIFs are presented in Table II. A total of 27 video sequences were created based on the variation and combination of the ffmpeg parameters, i.e., resolution $(858 \times 480,1280 \times 720$, $1280 \times 960)$, CTU $(16,32,64)$, and CRF $(18,28,38)$.

These video sequences were used for video streaming emulation over LTE, which was performed in LTE/EPC network simulator (LENA) using EvalVid framework. LENA represents LTE module of open source network simulator 3 (ns3) [39], which enables modelling of different communication networks and flexible user interfaces, modularity and scalability of architecture based on $\mathrm{C}++$ and Python. LENA allows design and evaluation of the performance of uplink and downlink routers, radio resource management algorithms, intercellular interference solutions, mobility management, and end-to-end QoE [40]. As such, it was used to generate network topology for video streaming. EvalVid was used as a tool to allow video streaming emulation and evaluation of its quality [41].

Emulation network topology is shown in Fig. 2. It consists of user equipment (UEs), eNodeB (eNB) in LTE radio access network, packet data network - gateway (PGW) in evolved packet core (EPC) network, and video server denoted as remote host. Table III summarizes configuration parameters of radio link (i.e., connection between UEs and eNodeB) and peer-topeer (p2p) link (i.e., connection between PGW and remote host). Network configuration parameters correspond to the macro base station [42], whereas carrier frequencies correspond to the European bandwidth [43]. Other LTE network parameters are set to ns-3 default values [39]. Video sequences 
TABLE I

SUMMARY OF RELATED WORK CONSIDERING THE IMPACT OF MEDIA-RELATED SIFS ON QOE FOR VIDEO STREAMING.

\begin{tabular}{|c|c|c|c|c|c|c|c|}
\hline Authors/ Reference & $\begin{array}{l}\text { Media-related } \\
\text { SIFs }\end{array}$ & Codec & Resolution & $\begin{array}{l}\text { Bitrate } \\
{[\text { kbps] }}\end{array}$ & $\begin{array}{c}\text { Frame rate } \\
\text { [fps] }\end{array}$ & $\begin{array}{c}\text { Quality } \\
\text { assessment }\end{array}$ & $\begin{array}{l}\text { Quality } \\
\text { metrics }\end{array}$ \\
\hline A. Aqil et al. [12] & $\begin{array}{l}\text { resolution } \\
\text { bitrate }\end{array}$ & H.264 & $\begin{array}{c}320 \times 200 \\
640 \times 350 \\
1280 \times 720 \\
1920 \times 1080\end{array}$ & $\begin{array}{c}111,236,293 \\
619,802 \\
1174,2433 \\
4656\end{array}$ & - & objective & PSNR \\
\hline A. Khan et al. [13] & $\begin{array}{l}\text { frame rate } \\
\text { bitrate }\end{array}$ & MPEG-4 & $176 \times 144$ & $\begin{array}{c}18,44,80 \\
104,512\end{array}$ & $10,15,30$ & $\begin{array}{l}\text { subjective } \\
\text { objective }\end{array}$ & $\begin{array}{l}\text { MOS } \\
\text { PSNR }\end{array}$ \\
\hline A. Khan et al. [14] & $\begin{array}{l}\text { frame rate } \\
\text { bitrate }\end{array}$ & H.264/AVC & $176 \times 144$ & $\begin{array}{l}48, \quad 88, \quad 128, \\
90,130,200 \\
256\end{array}$ & $7.5,10,15$ & $\begin{array}{l}\text { subjective } \\
\text { objective }\end{array}$ & $\begin{array}{l}\text { MOS } \\
\text { PSNR }\end{array}$ \\
\hline $\begin{array}{l}\text { A.Vakili and J.C. } \\
\text { Grégorie [15] }\end{array}$ & $\begin{array}{l}\text { frame rate } \\
\text { bitrate }\end{array}$ & Н.264 & $176 \times 144$ & - & $5,10,15,30$ & subjective & MOS \\
\hline C. Alberti et al. [16] & $\begin{array}{c}\text { frame rate } \\
\text { bitrate } \\
\text { sampling rate }\end{array}$ & $\begin{array}{l}\text { MPEG-4 } \\
\text { AVC }\end{array}$ & $1280 \times 720$ & $0.5,1,2,4,8$ & $7,10,15,30$ & subjective & MOS \\
\hline $\begin{array}{l}\text { D. Hammerschmidt and } \\
\text { C. Wöllner [17] }\end{array}$ & $\begin{array}{c}\text { resolution } \\
\text { frame rate } \\
\text { synchronization }\end{array}$ & Н.264 & $\begin{array}{c}320 \times 240 \\
480 \times 360 \\
1280 \times 720\end{array}$ & - & 24,30 & subjective & {$[-3,3]$} \\
\hline D. Vranješ et al. [18] & $\begin{array}{l}\text { resolution } \\
\text { frame rate } \\
\text { bitrate } \\
\text { codec }\end{array}$ & $\begin{array}{l}\text { H.264/AVC } \\
\text { SVC } \\
\text { WSVC }\end{array}$ & $\begin{array}{c}320 \times 180 \\
640 \times 360 \\
1280 \times 720\end{array}$ & $\begin{array}{c}520,768 \\
1024,3048\end{array}$ & $\begin{array}{c}6.25,12.5,25, \\
50\end{array}$ & objective & $\begin{array}{c}\text { SSIM } \\
\text { MS-SSIM } \\
\text { VQM } \\
\text { VSNR } \\
\text { PSNR }\end{array}$ \\
\hline I. Silvar et al. [19] & $\begin{array}{l}\text { frame rate } \\
\text { bitrate }\end{array}$ & H.264 & $1280 \times 720$ & $\begin{array}{l}3000,5000 \\
10000\end{array}$ & $15,20,25,30$ & subjective & MOS \\
\hline $\begin{array}{l}\text { J. Joskowicz and J. Ardao } \\
\text { [20] }\end{array}$ & $\begin{array}{l}\text { resolution } \\
\text { bitrate } \\
\text { codec }\end{array}$ & $\begin{array}{l}\text { MPEG-2 } \\
\text { H.264/AVC }\end{array}$ & $\begin{array}{l}720 \times 576 \\
640 \times 480 \\
352 \times 288 \\
176 \times 144\end{array}$ & {$[25,12000]$} & 25 & subjective & MOS \\
\hline $\begin{array}{l}\text { J. Joskowicz and J. Ardao } \\
\text { [21] }\end{array}$ & $\begin{array}{l}\text { resolution } \\
\text { frame rate } \\
\text { bitrate }\end{array}$ & H.264/AVC & $\begin{array}{l}720 \times 576 \\
640 \times 480 \\
352 \times 288 \\
176 \times 144\end{array}$ & {$[25,6000]$} & $\begin{array}{l}6.25,12.5,5 \\
25\end{array}$ & subjecitve & MOS \\
\hline J. Joskowicz et al. [22] & $\begin{array}{l}\text { resolution } \\
\text { bitrate } \\
\text { codec }\end{array}$ & $\begin{array}{l}\text { MPEG-2 } \\
\text { H.264/AVC }\end{array}$ & $\begin{array}{l}720 \times 576 \\
640 \times 480 \\
352 \times 288 \\
176 \times 144\end{array}$ & {$[50,12000]$} & 25 & subjective & MOS \\
\hline J. R. Ohm et al. [23] & $\begin{array}{l}\text { resolution } \\
\text { frame rate } \\
\text { codec }\end{array}$ & $\begin{array}{c}\text { H.262/MPEG- } \\
2 \text { MT } \\
\text { MPEG-4 ASP } \\
\text { H.263 CHC } \\
\text { MPEG-4 } \\
\text { Visual } \\
\text { H.264/MPEG- } \\
\text { 4 AVC } \\
\text { HEVC MP }\end{array}$ & $\begin{array}{c}2560 \times 1000 \\
1920 \times 1080 \\
832 \times 480 \\
416 \times 240 \\
1280 \times 720\end{array}$ & - & $24,30,50,60$ & $\begin{array}{l}\text { subjective } \\
\text { objective }\end{array}$ & $\begin{array}{l}\text { MOS } \\
\text { PSNR }\end{array}$ \\
\hline M. Řeřábek et al. [24] & $\begin{array}{l}\text { resolution } \\
\text { frame rate } \\
\text { bitrate } \\
\text { codec }\end{array}$ & $\begin{array}{c}\text { H.265/HEVC } \\
\text { VP9 } \\
\text { H.264/AVC }\end{array}$ & $\begin{array}{c}1280 \times 720 \\
1920 \times 1080\end{array}$ & $\begin{array}{c}256,384,512 \\
850,1000 \\
1600,2000 \\
2500,3000 \\
4500\end{array}$ & $30,50,60$ & $\begin{array}{l}\text { subjective } \\
\text { objective }\end{array}$ & $\begin{array}{l}\text { MOS } \\
\text { PSNR }\end{array}$ \\
\hline M. Uhrina et al. [25] & $\begin{array}{l}\text { bitrate } \\
\text { codec }\end{array}$ & $\begin{array}{l}\text { H.265/HEVC } \\
\text { H.264/AVC }\end{array}$ & $3840 \times 2160$ & {$[2000,30000]$} & 30 & objective & $\begin{array}{l}\text { PSNR } \\
\text { SSIM } \\
\text { VQM }\end{array}$ \\
\hline P. McDonagh et al. [26] & $\begin{array}{l}\text { resolution } \\
\text { frame rate }\end{array}$ & H.264 SVC & $\begin{array}{l}704 \times 576 \\
352 \times 280 \\
176 \times 144\end{array}$ & - & $7.5,15,30$ & objective & $\begin{array}{l}\text { PSNR } \\
\text { SSIM } \\
\text { blocking } \\
\text { blurring }\end{array}$ \\
\hline $\begin{array}{l}\text { P. Seeling and } \mathrm{M} . \\
\text { Reisslein [27] }\end{array}$ & $\begin{array}{l}\text { bitrate } \\
\text { codec }\end{array}$ & $\begin{array}{c}\text { H.265/HEVC } \\
\text { H.264/AVC }\end{array}$ & $1920 \times 1080$ & {$[1000,50000]$} & 24,30 & objective & PSNR \\
\hline R. M. Naisri et al [28] & $\begin{array}{l}\text { resolution } \\
\text { frame rate } \\
\text { sampling rate }\end{array}$ & Н.264 & $\begin{array}{l}1920 \times 1080 \\
640 \times 480\end{array}$ & - & $\begin{array}{l}5,10,15,30 \\
45,60\end{array}$ & subjective & MOS \\
\hline T. Zinner et al. [29] & $\begin{array}{l}\text { resolution } \\
\text { frame rate }\end{array}$ & H.264 SVC & $\begin{array}{c}480 \times 270 \\
640 \times 360 \\
960 \times 540 \\
1216 \times 684\end{array}$ & - & $\begin{array}{l}1.875,3.75 \\
7.5,15,30\end{array}$ & objective & $\begin{array}{l}\text { VQM } \\
\text { SSIM }\end{array}$ \\
\hline $\begin{array}{l}\text { W. Songi and W.D. } \\
\text { Tjondronegoro [30] }\end{array}$ & $\begin{array}{l}\text { resolution } \\
\text { frame rate }\end{array}$ & H.264/AVC & $\geq 1280 \times 720$ & $>3500$ & $12.5,25$ & objective & $\begin{array}{l}\text { PSNR } \\
\text { VQM } \\
\text { SSIM }\end{array}$ \\
\hline Y. F. Ou et al. [31] & $\begin{array}{c}\text { frame rate } \\
\text { sampling rate }\end{array}$ & H.264 SVC & $352 \times 288$ & - & $\begin{array}{l}1.875,3.75 \\
7.5,15,30 \\
\end{array}$ & subjective & MOS \\
\hline
\end{tabular}

Legend: ASP (Advanced Simple Profile); AVC (Advanced Video Coding); CHC (Conversational High Compression); HEVC (High Efficiency Video Coding); MOS (Mean Opinion Score); MP (Main Profile); MS-SSIM (Multi-Scale SSIM); MPEG (Moving Picture Experts Group); MT (Multi-Threaded); SIF (System Influence Factors); SSIM (Structural Similarity); SVC (Scalable Video Coding); PSNR (Peak Signal to Noise Ratio); VQM (Video Quality Metric); VSNR (Visual Signal-to-Noise Ratio); WSVC (Wireless Scalable Video Coding). 
TABLE II

RELATIONSHIP BETWEEN FFMPEG PARAMETERS AND SELECTED MEDIA-RELATED SIFs.

\begin{tabular}{|c|c|c|c|}
\hline $\begin{array}{l}\text { ffimpeg } \\
\text { parameter }\end{array}$ & Definition of $f f m p e g$ parameter & $\begin{array}{l}\text { Chosen ffmeg parameter } \\
\text { values }\end{array}$ & $\begin{array}{l}\text { Selected media-related } \\
\text { SIFs }\end{array}$ \\
\hline CTU & maximal size of coding unit & $16,32,64$ & coding \\
\hline CRF & $\begin{array}{l}\text { define the level of video quality by setting bitrate, } \\
\text { compression and sampling rate to the corresponding values } \\
\text { depending on the video and the defined CRF value }\end{array}$ & $18,28,38$ & $\begin{array}{l}\text { bitrate, compression, } \\
\text { sampling rate }\end{array}$ \\
\hline WxH resolution & video size in two dimensions & $858 \times 480,1280 \times 720,1280 \times 960$ & resolution \\
\hline
\end{tabular}

Legend: CRF (Constant Rate Factor); CTU (Coding Three Unit); SIFs (System Influence Factors).

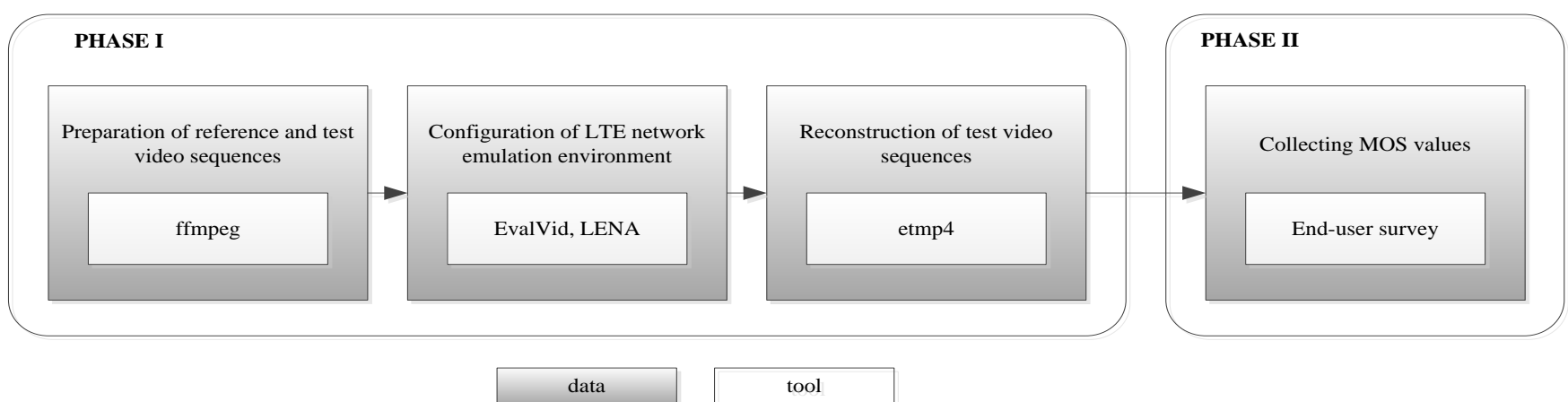

Fig. 1. Experimental procedure.

were transmitted in such network environment, and finally reconstructed using etmp4 tool from EvalVid framework.

\section{B. End-User Survey}

The second phase implies the measurement of subjective quality metric (i.e., MOS) for 27 video sequences prepared in the first phase. According to ITU-T recommendation G.1011, constant presentation and passive modality were used, while the

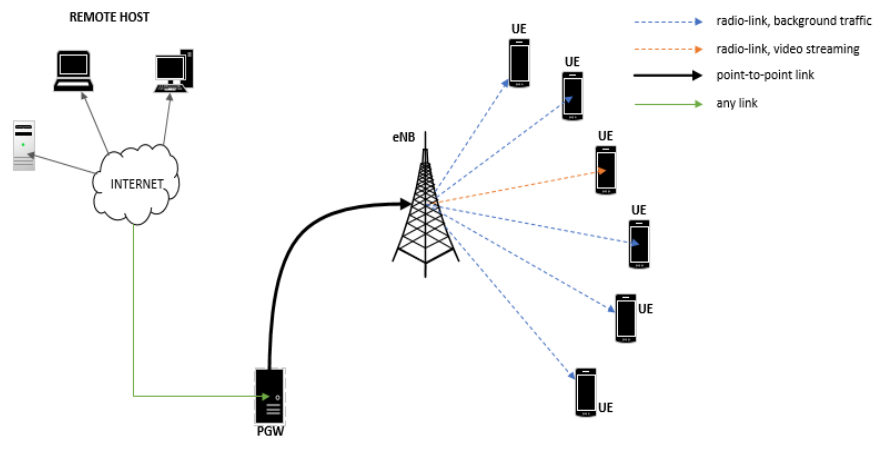

Fig. 2. Emulation network topology.

TABLE III

LTE NETWORK CONFIGURATION PARAMETERS.

\begin{tabular}{lll}
\hline \hline & Parameter & Values \\
\hline & carrier frequency & downlink $2110 \mathrm{MHz}$ \\
radio & & uplink $1920 \mathrm{MHz}$ \\
link & base station power & $46 \mathrm{dBm}(4 \mathrm{~W})$ \\
& resource blocks & $100 \mathrm{RB}(20 \mathrm{MHz})$ \\
& user moving speed & $3 \mathrm{~km} / \mathrm{h}$ \\
& bandwidth & $80 \mathrm{Mbps}$ \\
$\mathbf{p 2 p}$ & MTU & $1500 \mathrm{~B}$ \\
link & delay & $0.01 \mathrm{~s}$ \\
& distance base station-user & $100 \mathrm{~m}$ \\
\hline \hline
\end{tabular}

Legend: MTU (Maximal Transfer Unit); p2p (point-to-point). subjective quality assessment was performed after the video sequences presentation. Test video sequences were displayed in no-reference (NR) mode [44], where only reconstructed video sequences were shown to the respondents.

A total of 50 examinees participated in the experimental study. Mostly those were the family members, friends, and colleagues and they participated in the experiment on a good will basis in their free time and for free. Experiments were conducted at home $(36 \%)$, work $(6 \%)$, or café $(58 \%)$. Collected demographic data related to age, gender, educational level, and prior experience describe the group that approached the questioning:

- $46 \%$ of examinees fit into the category of age 15 to 24 , $30 \%$ into the category age 25 to $34,12 \%$ into the category age 35 to 44 , and $12 \%$ into the category age 44 to 55 ;

- $36 \%$ of examinees were male and $64 \%$ of them were female;

- $14 \%$ of examinees reported as having a high-school diploma, $28 \%$ reported as being students, $40 \%$ as having faculty degree, $14 \%$ of them as having a master of science degree, and $4 \%$ of them as having a doctor of philosophy degree;

- $58 \%$ of examinees said they use video streaming service on a daily basis, $14 \%$ said they use it every 2-3 days, $16 \%$ said they use it once a week, $10 \%$ said they use it once a month, whereas $2 \%$ said they did not use it at all.

All participants were given a task of watching 27 video sequences by using the Samsung Galaxy S4 mobile phone with $1920 \times 1080$ screen size. After that, they were asked to express their opinion regarding quality perception of video streaming service.

The subjective quality assessment of video sequences was performed by using the electronic evaluation questionnaire, 
which contained the part that was completed at the beginning of the experiment, and it included questions that covered information related to examinee's personal data and prior experience with video streaming service, and the part that deals with the examinee's ratings of the statement related to overall QoE when using video streaming service. The latter statement was a simple MOS scale used as the de facto standard in QoE studies and specified in ITU-T Recommendation P.800.1.

The experiment procedure lasted about 30 minutes and included the following three steps [45]: (i) introduction and clarification of the experiment tasks that need to be performed by the examinee ( 5 minutes), (ii) examinee training (5 minutes), and (iii) testing and rating of video sequences (20 minutes). Video sequences have been displayed in the landscape mode and in the same order to all examinees. All examinees were asked not to think about their feelings during evaluation, but to be intuitive.

\section{RESULTS AND DISCUSSION}

In order to statistically analyse the set of hypotheses (H1H7) stating that difference in QoE for video streaming over LTE caused by the change in individual parameters (i.e., resolution, CTU, and $\mathrm{CRF}$ ) and their interactions are not statistically significant, we used the three-way ANOVA [8]. A three-way ANOVA has been conducted with MOS as a dependent variable (DV), and resolution, CTU, and CRF as independent variables (IV). The analysis has been performed by using the trial version of the Statistical Package for the Social Sciences (SPSS) Statistics 20 software [46].

As stated in the Introduction section, we have used ANOVA given that we wanted to find out how our numerical $\mathrm{DV}$, i.e., QoE in MOS is related to our three categorical IVs (CTU, CRF, and resolution) and that is exactly what this statistical method is for, as described in [8, ch 1]. Further, for testing our eighth hypothesis we decided to use the MLR, given that we want to find out how our numerical DV is related to our several predictor variables which are numerical.

The collected data satisfies the presumptions of ANOVA (i.e., normally distributed variables, independent observations, and homogeneity). In order to assess the assumption that the residuals are normally distributed, we plotted the normal probability plots and presented it in Fig. 3. In this plot, the ordered values of the standardized residuals are plotted against the expected values from the standard normal distribution. If the residuals are normally distributed, they should lie, approximately, on the diagonal, as it is the case [47]. Next, in order to test the data for independence, we calculated the Durbin-Watson statistics that is used to test the presence of serial correlation among the residuals. The value of DurbinWatson statistic ranges from 0 to 4 . As a general rule of thumb, the residuals are uncorrelated if the Durbin-Watson statistic is approximately 2 . A value close to 0 indicated strong positive correlation, while a value of 4 indicates a strong negative correlation. The values of Durbin-Watson statistics for the data were in the range from 1.850 to 1.930 , which indicates no serial correlation [48]. The represented case, i.e., the data used for testing the hypotheses and producing the
QoE model obtained by consideration of media-related SIFs, has a Durbin-Watson value of 1.890. Finally, to assess homoscedasticity assumption, we plotted the predicted values against the residuals. According to [49], if the residuals are randomly scattered around 0 , i.e., the horizontal line, and thereby provide a relatively even distribution, we may conclude that the assumption is satisfied. As it can be seen in Fig. 4, the data in the shown case satisfies the assumption.

In statistics, an interaction may arise when considering the relationship among three or more variables, and describes a situation in which the simultaneous influence of two or more variables on additional one is not additive [50]. In an experiment with more than one factor, such as this study is (we consider simultaneous impact of resolution, CTU and CRF on MOS), as it is evident from the above hypothesis, these interaction effects between factors are another aspect to consider. An interaction means that independent variables, which are in our case previously mentioned resolution, CTU, and CRF, do not have only independent effect, but they have a complex and interactive influence on the dependent variable, which in our case is MOS value. An interaction between IVs means that the effect of one of those variables on DV is not constant - the main effect differs at different values of other [8, ch 2.].

In other words, suppose we have two binary factors A and B. For example, these factors might indicate male or female teacher (A) and male or female student (B). One can then consider the average math score for each student as a function of these factors (DV). Interaction effect is present on scores in math (DV) when the effect of factor A (male or female teacher)

is different across the levels of the factor B (being male or female student). Therefore, the difference in math scores between those students that are male and those that are female (factor B) is not the same and depends on whether they have been thought by male or female teacher (factor A) [50].

In our work we do not examine whether the considered IVs correlate with DV because the correlation between two variables means that the values of one variable relate in some way to the values of the other and not whether they interact in their effect on a third variable [51]. However, we used the Pearson correlation test in order to test the MLR assumption linearity, which will be explained in the second part of this chapter.

Table IV summarizes the results of the statistical analysis (ANOVA). As stated in Section III, the null hypothesis for ANOVA is that all population means are exactly equal. If this holds, then our sample means will probably differ a bit. A number that tell us how different are sample means is the variance.

The sums of squares between expresses the total amount of dispersion among the sample means and is calculated by the following equation [52]:

$S S_{\text {between }}=\sum n_{j}\left(\bar{X}_{J}-\bar{X}\right)^{2}$,

where $\bar{X}_{J}$ denotes a group mean, $\bar{X}$ is the overall mean, and $n_{j}$ is 
the sample size per group. Dividing the sum of squares between by its degree of freedom $(d f)$ results in mean squares between [52]:

$M S_{\text {between }}=\frac{S S_{\text {between }}}{d f_{\text {between }}}$

Mean squares between is basically the variance among sample means. When comparing $k$ means, the degrees of freedom is $(k-1)$.

On the other hand, the sum of squares within indicates the total amount of dispersion within groups and is calculated by [52]:

$S S_{\text {within }}=\sum\left(X_{i}-\bar{X}_{J}\right)^{2}$

where $\bar{X}_{J}$ denotes a group mean, and $X_{i}$ denotes an individual observation. Dividing the sum of squares within by its degree of freedom $(d f)$ results in mean squares between [52]:

$M S_{\text {within }}=\frac{S S_{\text {within }}}{d f_{\text {within }}}$

Mean square within is basically the variance within groups. For $n$ independent observations and $k$ groups, degree of freedom within is $(n-k)$.

The $F$-statistics represents the ratio of the between-group variance to the within-group variance and is computed by (9) [52]:

$$
F=\frac{M S_{\text {between }}}{M S_{\text {within }}}
$$

If $F$-statistics is large, the null hypothesis can be rejected. Since $F$-statistics itself is not interesting, it can be used to obtain the statistical significance if it follows $F$-distribution (which means that presumptions of ANOVA are met).

Statistical significance referred to as the $p$-value is the probability of finding a given deviation from the null hypothesis. The convention is that the $p$-value should be smaller than 0.05 for the $F$-statistics to be significant. If this is the case $(p<0.05)$, the null hypothesis should be rejected.

While the $p$-value tell us whether the difference between the conditions is statistically significant, partial eta square $\left(\eta_{p}^{2}\right)$ gives us the idea of how different are the means. As such, we refer to this as a measure of effect size [52]:

$\eta^{2}=\frac{S S_{\text {between }}}{S S_{\text {between }}+S S_{\text {within }}}$

Some rules of thumbs are that $\eta_{p}^{2}=0.032$ indicates a small effect, $\eta_{p}^{2}=0.060$ indicates a medium effect, and $\eta_{p}^{2}=0.14$ indicates a large effect.

According to Table IV, the results of the three-way ANOVA for MOS show that there exists statistically significant interaction of resolution, CTU, and CRF parameters with medium effect size in terms of practical significance.

The existence of this statistically significant interaction conditioned the performance of two-way ANOVA analysis for all parameters. After conducting the two-way ANOVA, we have plotted Fig. 5 - Fig. 13, which tend to provide a good graphical illustration of obtained results. An interaction effect can usually be seen as a set of non-parallel lines. One can noticed from Fig. 5 - Fig. 13 that the lines do not appear to be parallel (with the lines actually crossing). Therefore, one might expect there to be a statistically significant interactions, which are confirmed in Table IV.

Fig. 5, Fig. 6, and Fig. 7 show how CTU and CRF parameters affect QoE. The effects for CTU interacts with CRF. That is, CTU affects CRF values differently. The line representing CRF value of 18 descent quite steeply from CTU value of 32 to CTU value of 64 (especially on Fig. 6), whereas lines representing other CRF values are much more horizontal. Since it depends on CRF, there is no the effect of CTU. So that is why we ignore the main effect of CTU - even if it is statistically significant. This main effect puts together the different effects for all CRF values and this obscures rather than clarifies how CTU really affects QoE.

There exists statistically significant interaction with low effect size between CTU and CRF parameters for resolution of $858 \times 480$. Statistically significant interactions led to further consideration of individual impacts of these parameters on QoE. By using post-hoc analysis, the following results were obtained. For all CTU values (i.e., 16, 32, and 64), lower CRF values lead to better QoE when using video streaming services. In general, for each CTU value, the CRF value affects the QoE for video streaming, as shown on Fig. 5.

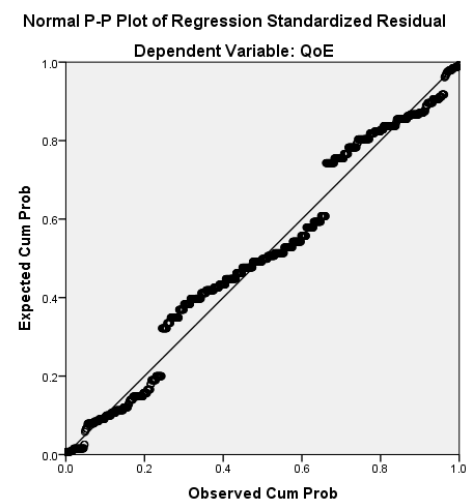

Fig. 3. Normal P-P plot of regression standardized residuals (normality assumption).

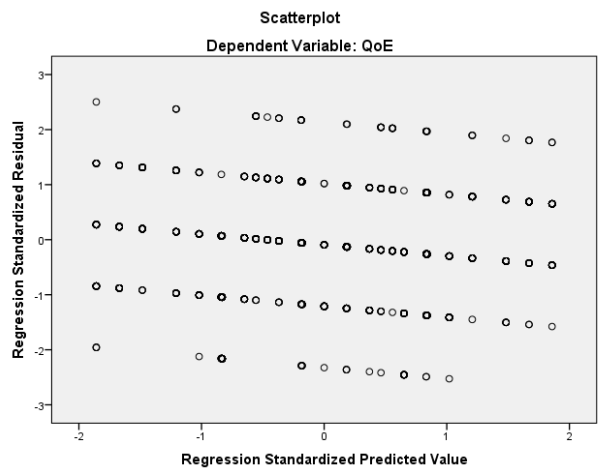

Fig. 4. Scatter plot of predicted values against the residuals (homoscedasticity). 
TABLE IV

SUMMARY OF STATISTICAL ANALYSIS RESULTS.

\begin{tabular}{|c|c|c|c|}
\hline \multicolumn{4}{|c|}{ Three-Way ANOVA } \\
\hline Influence factor & $F(1,441)$ & $\mathrm{p}(\alpha=0.05)$ & $\eta_{p}^{2}$ \\
\hline Interaction of resolution, CTU, and CRF & 19.780 & $<0.001$ & 0.107 \\
\hline \multicolumn{4}{|c|}{ Two-Way ANOVA } \\
\hline Influence factor & $F(1,441)$ & $\mathrm{p}(\boldsymbol{\alpha}=\mathbf{0 . 0 5})$ & $\eta_{p}^{2}$ \\
\hline Interaction of CTU and CRF (resolution $-858 \times 480$ ) & 2.949 & 0.02 & 0.026 \\
\hline Interaction of CTU and CRF (resolution - $1280 \times 720$ ) & 53.596 & $<0.001$ & 0.327 \\
\hline Interaction of CTU and CRF (resolution - $1280 \times 960$ ) & 28.397 & $<0.001$ & 0.205 \\
\hline Interaction of resolution and CRF (CTU - 16) & 11.729 & $<0.001$ & 0.096 \\
\hline Interaction of resolution and $\mathrm{CRF}$ (CTU - 32) & 28.726 & $<0.001$ & 0.207 \\
\hline Interaction of resolution and $\mathrm{CRF}$ (CTU - 64) & 34.677 & $<0.001$ & 0.239 \\
\hline Interaction of resolution and CTU (CRF - 18) & 39.121 & $<0.001$ & 0.262 \\
\hline Interaction of resolution and CTU (CRF - 28) & 24.394 & $<0.001$ & 0.181 \\
\hline Interaction of resolution and CTU (CRF - 38) & 4.568 & $<0.001$ & 0.040 \\
\hline \multicolumn{4}{|c|}{ One-way ANOVA } \\
\hline Influence factor & $F(1,441)$ & $\mathrm{p}(\alpha=0.05)$ & $\eta_{p}^{2}$ \\
\hline CRF (resolution $-858 \times 480$ and CTU -16 ) & 15.257 & $<0.001$ & 0.065 \\
\hline CRF (resolution $-858 \times 480$ and CTU -32 ) & 34.924 & $<0.001$ & 0.137 \\
\hline CRF (resolution $-858 \times 480$ and CTU -64 ) & 11.778 & $<0.001$ & 0.051 \\
\hline CRF (resolution - $1280 \times 720$ and CTU - 16) & 29.194 & $<0.001$ & 0.117 \\
\hline CRF (resolution $-1280 \times 720$ and CTU - 32) & 43.747 & $<0.001$ & 0.166 \\
\hline CRF (resolution $-1280 \times 720$ and CTU -64 ) & 78.466 & $<0.001$ & 0.262 \\
\hline CRF (resolution $-1280 \times 960$ and CTU -16 ) & 5.994 & 0.003 & 0.026 \\
\hline CRF (resolution - 1280×960 and CTU - 32) & 48.532 & $<0.001$ & 0.180 \\
\hline CRF (resolution $-1280 \times 960$ and CTU - 64) & 12.547 & $<0.001$ & 0.054 \\
\hline Resolution (CTU - 16 and CRF - 18) & 0.479 & 0.620 & 0.002 \\
\hline Resolution (CTU - 16 and CRF - 28) & 34.559 & $<0.001$ & 0.135 \\
\hline Resolution (CTU - 16 and CRF - 38) & 4.953 & 0.007 & 0.022 \\
\hline Resolution (CTU - 32 and CRF - 18) & 3.262 & 0.039 & 0.015 \\
\hline Resolution (CTU - 32 and CRF - 28) & 15.406 & $<0.001$ & 0.065 \\
\hline Resolution (CTU - 32 and CRF - 38) & 45.581 & $<0.001$ & 0.171 \\
\hline Resolution (CTU - 64 and CRF - 18) & 79.099 & $<0.001$ & 0.264 \\
\hline Resolution (CTU - 64 and CRF - 28) & 5.337 & 0.005 & 0.024 \\
\hline Resolution (CTU - 64 and CRF - 38) & 16.261 & $<0.001$ & 0.069 \\
\hline CTU (resolution $-858 \times 480$ and CRF -18 ) & 0.570 & 0.566 & 0.003 \\
\hline CTU (resolution $-1280 \times 720$ and CRF -18 ) & 3.744 & 0.024 & 0.017 \\
\hline CTU (resolution - 1280×960 and CRF - 18) & 101.661 & $<0.001$ & 0.316 \\
\hline CTU (resolution $-858 \times 480$ and CRF - 28 ) & 39.720 & $<0,001$ & 0.153 \\
\hline CTU (resolution $-1280 \times 720$ and CRF - 28) & 17.077 & $<0.001$ & 0.072 \\
\hline CTU (resolution - $1280 \times 960$ and CRF - 28) & 6.625 & $<0.001$ & 0.029 \\
\hline CTU (resolution $-858 \times 480$ and CRF -38 ) & 3.713 & 0.025 & 0.017 \\
\hline CTU (resolution - $1280 \times 720$ and CRF -38) & 32.952 & $<0.001$ & 0.130 \\
\hline CTU (resolution $-1280 \times 960$ and CRF - 38) & 13.164 & $<0.001$ & 0.056 \\
\hline
\end{tabular}

Legend: ANOVA (Analysis of Variance); CRF (Constant Rate Factor); CTU (Coding Tree Unit); QoE (Quality of Experience).

Also, there exists statistically significant interaction between CTU and CRF parameters for resolution $1280 \times 720$, but with large practical significance. As in the previous case (and every subsequent one), the impact of individual parameters on QoE for video streaming service has been considered. The results are different compared to the higher resolution, as shown on the Fig. 6. For all CTU values (i.e., 16, 32, and 64), higher CRF values lead to better QoE when using video streaming services.

Furthermore, there exists statistically significant interaction between CTU and CRF parameters for the resolution $1280 \times 960$ with large practical significance. In addition, as in the previous case, for all CTU values (i.e., 16, 32, and 64) the results show that CRF values affect the QoE when using the video streaming service (Fig. 7).
Fig. 8, Fig. 9, and Fig. 10 show how CRF and resolution affect QoE. The effect for CRF interacts with resolution. That is, CRF affects resolution differently. The line representing resolution of $858 \times 480$ descent quite steeply from CRF value of 18 to CRF value of 38 (especially on Fig. 9), whereas other resolutions are represented by broken lines. Since it depends on resolution, there is no the effect of CRF. So that is why we ignore the main effect of CRF - even if it is statistically significant. The main effect put together the different effects for all resolutions and this obscures rather than clarifies how CRF really affects QoE.

There exists statistically significant interaction with medium practical significance between resolution and CRF for CTU value 16. For CRF value 18, the resolution does not affect QoE. 
As shown on the Fig. 8, for CRF values 28 and 38, higher resolution values result in better QoE.

For CTU value 32 there exist statistically and practically significant interaction between resolution and CRF. Fig. 9 shows that for all CRF values (i.e., 18, 28, and 38), higher values of resolution lead to better QoE when using video streaming service.

Also, there exists statistically and practically significant interaction between resolution and CRF for CTU value 64. As in the previous case, for all CRF values (i.e., 18, 28, and 38), higher resolution leads to better QoE when using video streaming service (Fig. 10).

Fig. 11, Fig. 12, and Fig. 13 show how CTU and resolution affect QoE. The effects for CTU interacts with resolution. That is, CTU affects resolution differently. The line representing resolution of $1280 \times 720$ descent quite steeply from CTU value of 32 to CTU value of 64 (especially on Fig. 11), whereas lines representing other resolutions are much more horizontal. Since it also depends on resolution, there is no the effect of CTU. So that is why we ignore the main effect of CTU - even if it is statistically significant.

Finally, there exist statistically and practically significant interaction between resolution and CTU for CRF value 18 . Furthermore, analysis of individual effects shows that for CTU value 16, resolution has no influence on QoE, while for the CTU values 32 and 64, higher resolution values lead to better QoE when using the video streaming service (Fig. 11).

Also, there exists statistically and practically significant interaction between resolution and CTU for CRF value 28 , and CRF value 38. For CRF value 28, it is shown that for all CTU values (Fig. 12) (i.e., 16, 32, and 64), higher resolution lead to better QoE when using video streaming. For CRF value 38, it is shown that the same is true (Fig. 13).

Also, if we approach to ANOVA in more general conceptual way, it is possible to have the GLM model written as the sum of a number of components which represent various aspects of an experiment. In case where we have, for example three factors, such as this study is, a mathematical expression representing data values in terms of the structure of the experiment is as follows [8, ch 5]:

$y_{i j k l}=\mu+C T U_{i}+C R F_{j}+(C T U \leftrightarrow C R F)_{i j}+R E S_{k}+$
$(C T U \leftrightarrow R E S)_{i k}+(C R F \leftrightarrow R E S)_{j k}+(C T U \leftrightarrow C R F \leftrightarrow R E S)_{i j k}+$
$S((C T U \leftrightarrow C R F \leftrightarrow R E S))_{i j k l}$,

where $y$ represents scores or data values, $\mu$ represents the baseline, $C T U, C R F, R E S$ effects of considered factors,

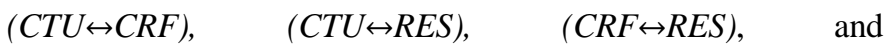
$(C T U \leftrightarrow C R F \leftrightarrow R E S)$ interaction effects, and $S$ is the error term.

Based on the previous results analysis, it is concluded that all null hypotheses $(\mathrm{H} 1-\mathrm{H} 7)$ have been rejected, since there exist statistically significant differences in QoE when using video streaming service for all individual parameter changes (i.e., resolution, CTU, and CRF) as well as changes caused by their interactions. In other words, there exist individual impact of resolution, CTU, and CRF parameters on QoE when using video streaming services. Furthermore, QoE for video streaming is affected by the interaction of pairs of considered parameters (resolution and CTU, resolution and CRF, CTU and CRF), and the simultaneous interaction of all three considered parameters.

Second part of our analysis is related to quantification of relations between QoE and addressed media-related SIFs, i.e., producing a prediction model with media-related SIFs as predictor variables and QoE as output variable. In other words, we want to describe the relation between QoE and these factors, and to test whether the variability of QoE is explained by the variability of the considered SIFs and to which degree. However, in order to proceed with this analysis, we must check our data if it satisfies the MLR assumptions. Given that they are the same as for ANOVA, we only add the Pearson correlation which proves the linearity assumption in Table V.

$Q o E=3.216-0.181 * C T U+0.116 * R E S+0.005 * C R F$.

As indicated by the results analysis, all considered mediarelated SIFs significantly contribute to describing the variability of QoE ( $p$-value in Table VI). The percent of variation of QoE can be accounted for by the knowledge of the considered media-related SIFs by approximately $37 \%\left(R^{2}\right)$, while the calculated coefficient of variation $(\%)$ is approximately $21 \%$. Such $R^{2}$ is expected given that it is hard to produce models for human behavior with high $R^{2}$ while at the same time not including human and context related parameters [53]. Based on the obtained results, it may be concluded that the proposed prediction model of QoE for video streaming represents quantification of mutual relations of selected media-related SIFs and QoE. We again note that measures of all factors are considered on a scale from 1-3, while QoE is also predicted as a value between 1 and 5 (MOS).

The obtained model given in Table VI and equation (12) supports the rejection of the hypothesis $\mathrm{H} 8$ since the degree to which each factor impacts QoE was not as we expected. According to regression coefficients and obtained model, we were able to identify the importance (impact degree) of distinct factors in terms of QoE. We have expected to have the order of impact degree as indicated by the literature review: CTU, CRF, and resolution. The order in which selected factors differ in their impact on the overall QoE (going from most to leas influential) in the context of video streaming is the following: CTU, resolution, CRF. In other words, the model for QoE for video streaming shows that the most important media-related SIF is found to be CTU, resolution, and CRF, respectively.

The value of $R^{2}$ is, as already stated, expected and confirms more important finding: QoE for video streaming is a multidimensional concept and needs to include context and human influence factors in order to be addressed and modelled properly. In addition, calculated coefficient of variation $(21 \%)$ indicates that the reported analysis could be used in QoE prediction, but additional investigations are needed on the impact of additional factors for the purpose of increasing accuracy. These findings are good basis for our future work, which will include multidimensional modelling of QoE that 


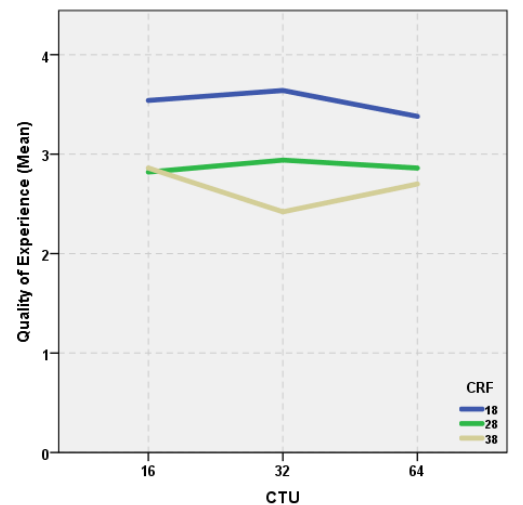

Fig. 5. Resolution $858 \times 480-$ interaction between CTU and CRF

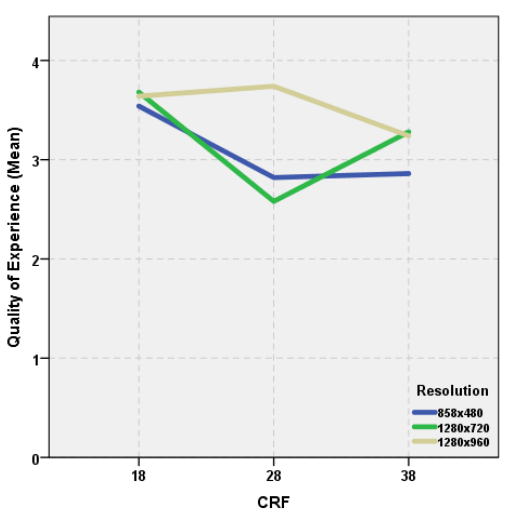

Fig. 8. CTU 16 - interaction between resolution and $\mathrm{CRF}$

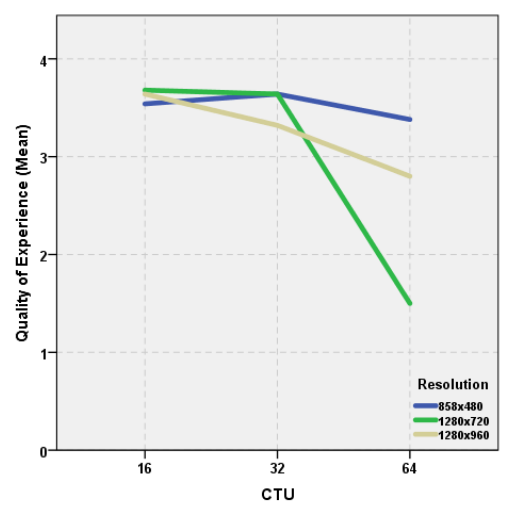

Fig. 11. CRF 18 - interaction between resolution and CTU.

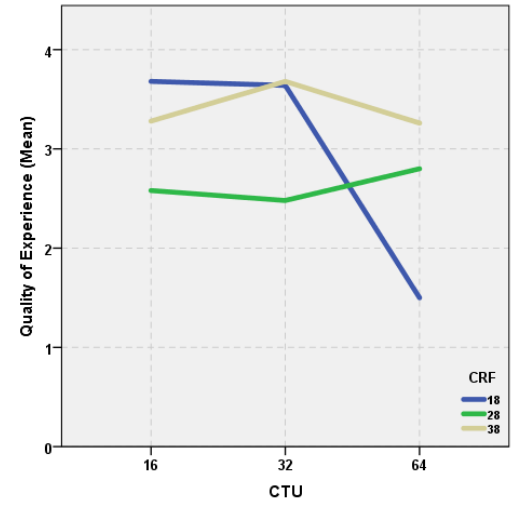

Fig. 6. Resolution $1280 \times 720$ - interaction between CTU and CRF.

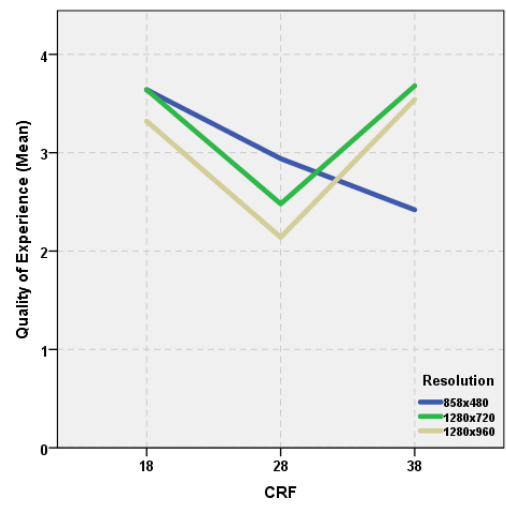

Fig. 9. CTU 32 - interaction between resolution and CRF.

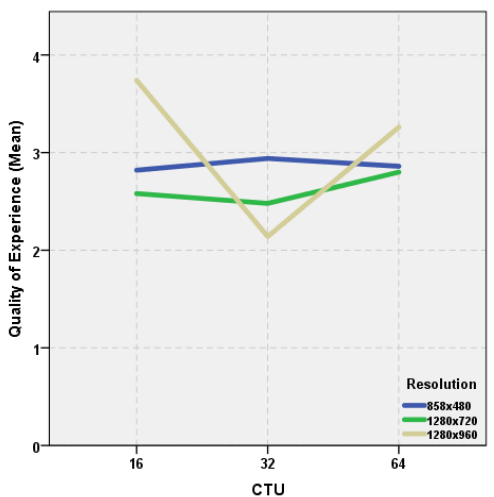

Fig. 12. CRF 28 - interaction between resolution and CTU.

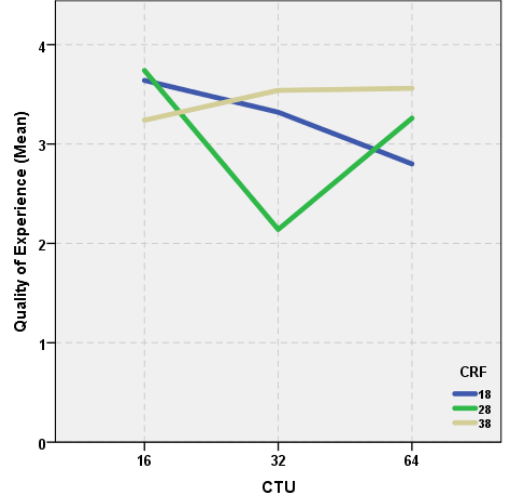

Fig. 7. Resolution $1280 \times 960$ - interaction between CTU and CRF.

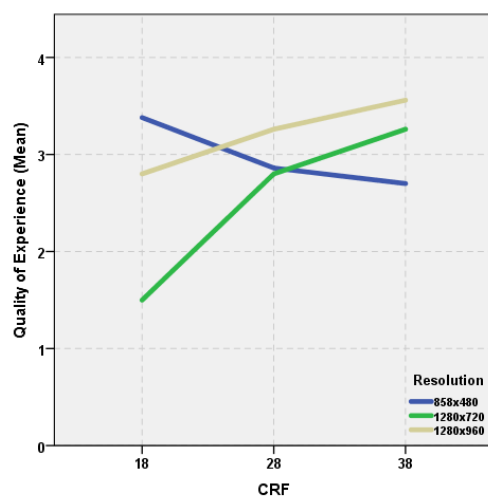

Fig. 10. CTU 64 - interaction between resolution and $\mathrm{CRF}$.

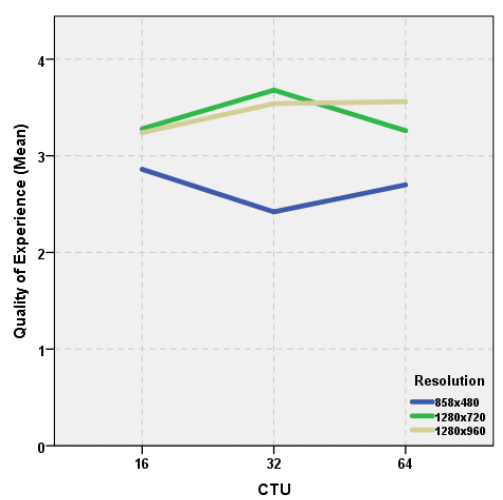

Fig. 13. CRF 38 - interaction between resolution and CTU. 
TABLE V

PEARSON CORRELATION COEFFICIENTS

\begin{tabular}{lllll}
\hline \hline & QoE & CTU & CRF & Resolution \\
\hline QoE & 1 & 0.550 & -0.862 & 0.103 \\
CTU & - & 1 & 0.747 & 0.162 \\
CRF & - & - & 1 & 0.145 \\
Resolution & - & - & - & 1 \\
\hline \hline
\end{tabular}

Legend: CRF (Constant Rate Factor); CTU (Coding Tree Unit); QoE (Quality of Experience).

TABLE VI

SUMMARY OF RESULTS OF MLR ANALYSIS FOR RELATION BETWEEN QOE AND MEDIA-RELATED SIFs.

\begin{tabular}{lccccc}
\hline \hline & Coeff. & $\begin{array}{c}\text { Std. } \\
\text { coeff. }\end{array}$ & $\begin{array}{c}\text { Std. } \\
\text { error }\end{array}$ & t & p-value \\
\hline Constant & 3.216 & & 0.088 & 36.542 & $<0.001$ \\
CTU & -0.181 & -0.162 & 0.030 & -6.058 & $<0.001$ \\
Resolution & 0.116 & 0.103 & 0.030 & 3.865 & $<0.001$ \\
CRF & 0.005 & 0.005 & 0.002 & 1.007 & 0.002 \\
\hline \hline
\end{tabular}

Legend: Coeff. (Coefficient); CRF (Constant Rate Factor); CTU (Coding Tree Unit); QoE (Quality of Experience); Std. (Standard).

will gain more accurate prediction equation. This prediction formula will include in addition to system IFs, several most important human IFs and context IFs, given the fact that as already stressed, that the QoE requires a multidimensional approach.

\section{CONCLUSION AND FUTURE WORK}

Growing trend of video streaming usage implies that mediarelated SIFs should be well understood in order to determine how they affect the user's QoE. There lies the motivation for this paper, which aims to provide a deeper understanding of impact of media-related SIFs and their interactions on QoE in the context of H.265/HEVC coded video streaming over LTE and to produce a prediction model for QoE in this context.

Therefore, non-exhaustive review of related works in the field of media-related SIFs and their impact on subjective/objective quality perception of video streaming was prepared. It has served us to select three media-related SIFs (i.e., resolution, bitrate, and compression) which were manipulated by changing ffmpeg parameters (i.e., resolution, CTU, and CRF) in order to create video sequences used in the experimental study.

Statistical analysis of data collected by end-user survey implies that there exist statistically and practically significant impact of individual parameters (i.e., resolution, CTU, and CRF) and their interaction on QoE when using H.265/HEVC video streaming service. Also, we have provided a quantification of relationship between media-related SIFs and QoE for H.265/HEVC video streaming, i.e., a prediction QoE model which shows that the most important media-related SIF is found to be CTU, resolution, and CRF, respectively.

The original scientific contribution of this study and its results is twofold. The study shows that the impact of mediarelated SIFs and their mutual interactions on QoE for
H.265/HEVC video streaming is strong and statistically and practically significant. Also, the relationship between selected media-related SIFs and QoE for H.265/HEVC video streaming is quantified. This is the first time that the description and quantification of abovementioned relations has been provided in such a manner. Consequently, based on the proposed model, one is able to identify the importance of distinct media-related SIFs in terms of QoE. However, more important is that we have confirmed that QoE needs to be approached as a multidimensional concept, i.e., we need to consider human and context IFs along with other system IFs.

The knowledge of these impacts and interactions, as well as the prediction model, can be used by interested stakeholders to become aware of and to understand how their work affects others in the service provisioning chain. In addition, they may utilize these findings to enhance their services and to improve their pieces of the QoE puzzle, which jointly lead to better end user's QoE.

However, our experimental study has certain limitations that may be overcome in the future work. Given the fact that video streaming over LTE is probably influenced by additional parameters except those three investigated in this paper, a broader range of various parameters and their interactions should be included in future research studies. Moreover, larger number of examinees should be included in the further studies in order to draw non-misleading conclusions. Since examinees involved in this study were instructed on what task to perform, the field studies should be performed in the future. In addition, the subject of future work should be the proposal of predictive multidimensional model for video streaming which may be helpful in a practical sense.

\section{REFERENCES}

[1] P. Corwall, et al., "Ericsson Mobility Report," Ericsson, Nov., 2017. [Online]. Available: https://www.ericsson.com/assets/local/mobilityreport/documents/2017/ericsson-mobility-report-november-2017.pdf

[2] E. Cero, J. Baraković Husić, and S. Baraković, "IoT's Tiny Steps towards 5G: Telco's Perspective," Symmetry, vol. 9, no. 10, 2017. DOI: 10.3390/sym9100213

[3] T. Begluk, J. Baraković Husić, and S. Baraković, "Machine learningbased QoE prediction for video streaming over LTE network," in Proc. of 17th International Symposium INFOTEH-JAHORINA, Jahorina, B\&H, Mar. 21-23, 2018. DOI: 10.1109/INFOTEH.2018.8345519

[4] K. Brunnström, et al., "Qualinet White Paper on Definitions of Quality of Experience," European Network on Quality of Experience in Multimedia Systems and Services, QUALINET (COST Action IC 1003), Novi Sad, Serbia, Mar. 13, 2013. [Online]. Available: https://hal.archives-ouvertes.fr/hal-00977812/document

[5] S. Baraković and L. Skorin-Kapov, "Survey of research on Quality of Experience modelling for web browsing," Quality and User Experience, vol. 2, no. 6, 2017. DOI: 10.1007/s41233-017-0009-2

[6] S. Baraković and L. Skorin-Kapov, "Survey and Challenges of QoE Management Issues in Wireless Network," Journal of Computer Networks and Communications, vol. 2013, 2013. DOI: 10.1155/2013/165146

[7] J. Blenik, M. Uhrina, M. Kuba, M. Vaculik, "Performance of H.264, H.265, VP8 and VP9 Compression Standards for High Resolutions," in Proc. of the $19^{\text {th }}$ International Conference on Network-Based Information Systems (NBiS), Ostrava, Czech Republic, Sept. 7-9, 2016. DOI: 10.1109/NBiS.2016.70

[8] J. Miller and P. Haden, Statistical Analysis with the General Linear Model. Creative Commons Attribution, 2006.

[9] J. Baraković Husić, S. Baraković, A. Veispahić, "What Factors Influence the Quality of Experience for WebRTC Video Calls?" in Proc. of $40^{\text {th }}$ 
International Convention on Information and Communication Technology, Electronics and Microelectronics (MIPRO), Opatija, Croatia, May 22-26, 2017. DOI: 10.23919/MIPRO.2017.7973463

[10] S. Baraković and J. Baraković Husić, "Web categorization and end user survey addressing mobile web," J. BH Elektrotehnika, vol. 10, pp. 3645, 2016.

[11] J. Nightingale, Q. Wang, C. Grecos, S. Goma, "The impact of network impairment on quality of experience (QoE) in H.265/HEVC video streaming," IEEE Transactions on Consumer Electronics, vol. 60, no. 2, pp. 242-250, 2014. DOI: 10.1109/TCE.2014.6852000

[12] A. Aqil, A. O. F. Atya, S. V. Krishnamurthy, and G. Papageorgiou, "Streaming Lower Quality Video over LTE: How Much Energy Can You Save?," in Proc. of the IEEE 23rd International Conference on Network Protocols (ICNP), San Francisco, CA, USA, Nov. 10-13, 2015. DOI: $10.1109 /$ ICNP.2015.50

[13] A. Khan, L. Sun, E. Jammeh, and E. Ifeachor, "Quality of experiencedriven adaptation scheme for video applications over wireless networks," IET communications, vol. 4, no. 11, pp. 1337-1347, 2010 DOI: $10.1049 /$ iet-com.2009.0422

[14] A. Khan, L. Sun, E. Ifeachor, J. O. Fajardo, F. Liberal, and H Koumaras, "Video quality prediction models based on video conten dynamics for H. 264 video over UMTS networks," International Journal of Digital Multimedia Broadcasting, 2010. DOI: 10.1155/2010/608138

[15] A.Vakili and J. C. Grégorie, "QoE management for video conferencing applications," Computer Networks, vol. 57, pp. 1726-1738, 2013. DOI: 10.1016/j.comnet.2013.03.002

[16] C. Alberti, et al., "Automated QoE evaluation of dynamic adaptive streaming over HTTP," in Proc. of the $5^{\text {th }}$ International Workshop on Quality of Multimedia Experience (QoMEX), Klagenfurt am Wörthersee, Austria, Jul. 3-5, 2013, pp. 58-63. DOI: 10.1109/QoMEX.2013.6603211

[17] D. Hammerschmidt and C. Wöllner, "The influence of image compression rate on perceived audio quality in music video-clips," in Proc. of International Conference on the multimodal Experience of Music (ICMEM), Sheffield, UK, Mar. 23-25, 2015.

[18] D. Vranješ, D. Žagar, and O. Nemčić, "Comparison of objective quality assessment methods for scalable video coding," in Proc. of the $54^{\text {th }}$ International symposium ELMAR-2012, Zadar, Croatia, Sept. 12-14, 2012. pp. 19-22.

[19] I. Silvar, M. Sužnjević, and L. Skorin-Kapov, "The impact of video encoding parameters and game type on QoE for cloud gaming: A case study using the steam platform," in Proc. of the $7^{\text {th }}$ International Workshop on Quality of Multimedia Experience (QoMEX), 2015, PylosNestoras, Greece, May 26-29, 2015, pp. 1-6. DOI 10.1109/QoMEX.2015.7148144

[20] J. Joskowicz and J. Ardao, "A general parametric model for perceptua video quality estimation," in Proc. of the International Workshop Technical Committee on Communications Quality and Reliability (CQR), 2010, Vancouver, BC, Canada, Jun. 8-10, 2010, pp. 1-6. DOI: 10.1109/CQR.2010.5619912

[21] J. Joskowicz and J. Ardao, "Combining the effects of frame rate, bit rate, display size and video content in a parametric video quality model," in Proc. of the $6^{\text {th }}$ Latin America Networking Conference, 2011, Quito, Ecuador, Oct. 12-13, 2011, pp. 4-11. DOI: 10.1145/2078216.2078218

[22] J. Joskowicz, J. C. L. Ardao, and R. Sotelo, "Quantitative modeling of the impact of video content in the ITU-T G. 1070 video quality estimation function," Informática na educação: teoria \& prática, vol. 14, no. 2, 2011. DOI: 10.22456/1982-1654.21825

[23] J. Ohm, G. J. Sullivan, H. Schwarz, T. K. Tan, and T. Weigand, "Comparison of the coding efficiency of video coding standardsincluding high efficiency video coding (HEVC)," IEEE Transactions on circuits and systems for video technology, vol. 22, pp. 1669-1684, 2012. DOI: 10.1109/TCSVT.2012.2221192

[24] M. Reřábek, P. Hanhart, P. Korshunov, T. Ebrahimi, “Quality evaluation of HEVC and VP9 video compression in real-time applications," in Proc. of the $7^{\text {th }}$ International Workshop on Quality of Multimedia Experience (QoMEX), 2015, Pylos-Nestoras, Greece, May 26-29, 2015, pp. 1-6. DOI: 10.1109/QoMEX.2015.7148088

[25] M. Uhrina, J. Frnda, L. Sevcik, M. Vaculik, "Impact of H. 264/AVC and H. 265/HEVC compression standards on the video quality for $4 \mathrm{~K}$ resolution," Advances in Electrical and Electronic Engineering, vol. 12, pp. 368-376, 2014. DOI: 10.15598/aeee.v12i4.1216

[26] P. McDonagh, C. Vallati, A. Pande, P. Mohapatra, P. Perry, E. Mingozzi, "Quality-oriented scalable video delivery using H. 264 SVC on an LTE network," in Proc. of the 14th International Symposium on
Wireless Personal Multimedia Communications (WPMC), 2011, Brest, France, Oct. 3-7, 2011. DOI: 10.1109/GLOCOM.2011.6133953

[27] P. Seeling and M. Reisslein, "Video traffic characteristics of modern encoding standards: H. 264/AVC with SVC and MVC extensions and H. 265/HEVC," The Scientific World Journal, vol. 16, 2014. DOI $10.1155 / 2014 / 189481$

[28] R. M. Nasiri, J. Wang, A. Rehman, S. Wang, Z. Wang, "Perceptual quality assessment of high frame rate video," in Proc. of the 17th International Workshop on Multimedia Signal Processing (MMSP), 2015, Xiamen, China, Oct. 19-21, 2015, pp. 1-6. DOI: 10.1109/MMSP.2015.7340831

[29] T. Zinner, O. Hohlfeld, O. Abboud, and T. Hossfeld, "Impact of frame rate and resolution on objective QoE metrics," in Proc. of the 2nd International Workshop on Quality of Multimedia Experience (QoMEX), 2010, Trondheim, Norway, Jul. 21-23, 2010, pp. 29-34. DOI: 10.1109/QOMEX.2010.5518277

[30] W. Songi and W. D. Tjondronegoro, “Acceptability-based QoE models for mobile video," IEEE Transactions on Multimedia, vol. 16, pp. 738750, 2014. DOI: 10.1109/TMM.2014.2298217

[31] Y. F. Ou, W. Lin, H. Zeng, and Y. Wang, "Perceptual Quality of Video with Periodic Frame Rate and Quantization Variation-Subjective Studies and Analytical Modeling," CoRR abs/1406.2018, 2014.

[32] D. Grois, D. Marpe, A. Mulayoff, B. Itzhaky, and O. Hadar, "Performance comparison of h. 265/mpeg-hevc, vp9, and h. 264/mpegavc encoders," in Proc. of Picture Coding Symposium (PCS), San Jose, CA, USA 2013. DOI: 10.1109/PCS.2013.6737766

[33] F. Kuipers, R. Kooij, D. De Vleeschauwer, and K. Brunnström, "Techniques for measuring quality of experience," in Proc. of the $8^{\text {th }}$ International Conference on Wired/Wireless Internet Communications (WWIC), 2010, Lulea, Sweden, Jun. 01-03, 2010, pp. 216-227. DOI: 10.1007/978-3-642-13315-2_18

[34] H. Al-Nuaim and A. Nouf, "A user perceived quality assessment of lossy compressed images," International Journal of Computer Graphics, vol. 2, pp. 23-36, 2011

[35] A. Khan, L. Sun, and E. Ifeachor, "QoE prediction model and its application in video quality adaptation over UMTS networks," IEEE Transactions on Multimedia, vol. 14, pp. 431-442, 2012. DOI: 10.1109/TMM.2011.2176324

[36] K. Zeng, T. Zhao, A. Rehman and Z. Wang, "Characterizing Perceptual Artifacts in Compressed Video Streams," in Proc. SPIE 9014, Human Vision and Electronic Imaging (HVEI) XIX, Jan. 2014. DOI: $10.1117 / 12.2043128$

[37] FFmpeg development team. (2018, Mar.). ffmpeg Documentation. [Online]. Available: https://ffmpeg.org/ffmpeg.html

[38] S. Rubel. Videezy. [Online]. Available at: https://www.videezy.com/ , 2017.

[39] NS-3 development team. 2017 [Online]. Available: https://www.nsnam.org/docs/manual/ns-3-manual.pdf

[40] P. Giuseppe, N. Baldo, and M. Miozzo, "An LTE Module for the ns-3 network simulator," in Proc. of the $4^{\text {th }}$ International ICST Conference on Simulation Tools and Techniques (SIMUTool'11), Mar. 2011.

[41] J. Klaue, B. Rathke, and A. Wolisz, "EvalVid - A Framework for Video Transmission and Quality Evaluation," In: Kemper P., Sanders W.H. (eds) Computer Performance Evaluation. Modelling Techniques and Tools (TOOLS 2003). Lecture Notes in Computer Science, vol 2794. Springer, Berlin, Heidelberg. DOI: 10.1007/978-3-540-45232-4_16

[42] S. N. Shahab, A. A. Abdulkafi, and A. R. Zainun, "Assessment of Area Energy Efficiency of LTE Macro Base Stations in Different Environments," Journal of Telecommunications and Information Technology, p. 59, 2015.

[43] M. Sauter, "Long Term Evolution," in From GSM to LTE: an introduction to mobile networks and mobile broadband, West Sussex, UK: John Wiley \& Sons, 2010.

[44] Methodology for the subjective assessment of the quality of television pictures, ITU-T Recommendation BT-500, 2012.

[45] S. Baraković and L. Skorin-Kapov, "Multidimensional Modelling of Quality of Experience for Mobile Web Browsing," Computers in Human Behaviour, vol. 50, pp. 314-332, 2015. DOI: 10.1016/j.chb.2015.03.071

[46] IBM development team. IBM SPSS Software. 2018. [Online]. Available: http://www-01.ibm.com/software/analytics/spss/

[47] Testing Assumptions of linear regression in SPSS. 2018. [Online] Available: http://www.statisticssolutions.com/testing-assumptions-oflinear-regression-in-spss/.

[48] A. J. Schwab, Course materials - Data analysis II. University of Texas, 2007. 
[49] O. Jason and E. Waters, "Four assumptions of multiple regression that researchers should always test" Practical Assessment, Research and Evaluation, 8(2), 2002.

[50] Interaction (statistics). 2018. [Online] Available: https://en.wikipedia.org/wiki/Interaction (statistics)

[51] K. Grace-Martin. The difference between interaction and association. 2018 [Online]. Available: https://www.theanalysisfactor.com/interaction-association

[52] SPSS Tutorials. ANOVA - Simple Introduction. 2018. [Online]. Available: https://www.spss-tutorials.com/anova-what-is-it/

[53] S.A. Sweet and K.A. Grace-Martin, "Data Analysis with SPSS. A First Course in Applied Statistics." 4th edition. Pearson, 2012.

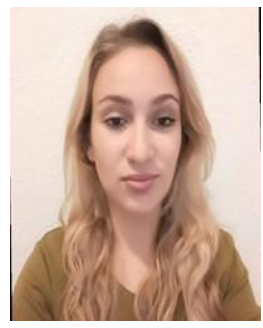

Irma Osmanović received her Bachelor Degree and Master Degree in Engineering at the Faculty of Electrical Engineering, University of Sarajevo in 2015 and 2017, respectively. In July, 2017, she started threemonth internship as Junior Network Engineer at Avacom Group Company. She is employed by Systech, Sarajevo, where she work as a software engineer. Her research interests include different topics related to QoS/QoE management in multimedia networks.

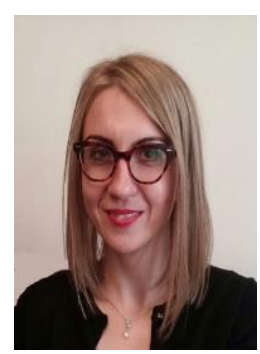

Jasmina Baraković Husić received her PhD degree in 2009 at the Faculty of Electrical Engineering and Computing, University of Zagreb. She is an Associate Professor at the Faculty of Electrical Engineering, University of Sarajevo. She is employed by BH Telecom, Joint Stock Company, Sarajevo as a specialist in the Department for Planning and Development of Technologies and Services. Her research interests include a variety of topics in signalling and QoS/QoE management in NGN, IoT, 5G communications.

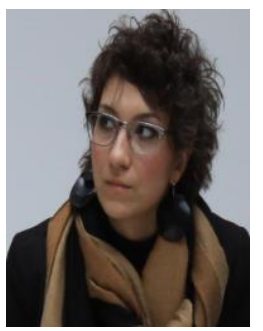

Sabina Baraković received her $\mathrm{PhD}$ degree in 2014 at the Faculty of Electrical Engineering and Computing, University of Zagreb. She is an expert adviser at the Ministry of Security of Bosnia and Herzegovina and an Assistant Professor at the University of Sarajevo and American University in Bosnia and Herzegovina. Her research interests include multidimensional QoE modelling of multimedia, mobile Web-based applications, and unified communications, and management of QoS/QoE in mobile and NGN environment. 